\title{
TERRESTRIAL LASER SCANNING FOR COASTAL GEOMORPHOLOGIC RESEARCH IN WESTERN GREECE
}

\author{
D. Hoffmeister ${ }^{\mathrm{a}, *}$, N. Tilly ${ }^{\mathrm{a}}$, C. Curdt ${ }^{\mathrm{a}}$, H. Aasen ${ }^{\mathrm{a}}$, K. Ntageretzis ${ }^{\mathrm{b}}$, H. Hadler ${ }^{\mathrm{b}}$, T. Willershäuser ${ }^{\mathrm{b}}$, A. Vött ${ }^{\mathrm{b}}$, G. Bareth $^{\mathrm{a}}$ \\ ${ }^{\text {a }}$ Institute of Geography, University of Cologne, Albertus-Magnus-Platz, 50923 Cologne, Germany - \\ (dirk.hoffmeister, n.tilly, h.aasen, c.curdt, g.bareth)@uni-koeln.de \\ ${ }^{\mathrm{b}}$ Institute of Geography, Johannes Gutenberg-University Mainz, Johann-Joachim-Becher-Weg 21, 55099 Mainz, \\ Germany - (konstantin.ntageretzis, hadler, timo.willershäuser, a.voett)@uni-mainz.de
}

KEY WORDS: TLS, Multitemporal, Geomorphology, Coast, Hazards, History

\begin{abstract}
:
We used terrestrial laser scanning (TLS) for (i) accurate volume estimations of dislocated boulders moved by high-energy impacts and for (ii) monitoring of annual coastal changes. In this contribution, we present three selected sites in Western Greece that were surveyed during a time span of four years (2008-2011). The Riegl LMS-Z420i laser scanner was used in combination with a precise DGPS system (Topcon HiPer Pro). Each scan position and a further target were recorded for georeferencing and merging of the point clouds. For the annual detection of changes, reference points for the base station of the DGPS system were marked.

Our studies show that TLS is capable to accurately estimate volumes of boulders, which were dislocated and deposited inland from the littoral zone. The mass of each boulder was calculated from this 3D-reconstructed volume and according density data. The masses turned out to be considerably smaller than common estimated masses based on tape-measurements and according density approximations. The accurate mass data was incorporated into wave transport equations, which estimate wave velocities of highenergy impacts. As expected, these show smaller wave velocities, due to the incorporated smaller mass.

Furthermore, TLS is capable to monitor annual changes on coastal areas. The changes are detected by comparing high resolution digital elevation models from every year. On a beach site, larger areas of sea-weed and sandy sediments are eroded. In contrast, bigger gravel with $30-50 \mathrm{~cm}$ diameter was accumulated. At the other area with bigger boulders and a different coastal configuration only slightly differences were detectable.

In low-lying coastal areas and along recent beaches, post-processing of point clouds turned out to be more difficult, due to noise effects by water and shadowing effects. However, our studies show that the application of TLS in different littoral settings is an appropriate and promising tool. The combination of both instruments worked well and the annual positioning procedure with own survey point is precose for this purpose.
\end{abstract}

\section{INTRODUCTION}

Coastal areas are under permanent change, for example caused by tides, coastal erosion, and anthropogenic impacts. Additionally, high energy events (strong storms or tsunamis) have an influence of the coastal configuration. In particular, western Greece is directly exposed to the Hellenic trench, which is a major tectonic zone in the eastern Mediterranean. Thus, the region is characterized by a high seismic and tsunamigenic hazard risk (Papazachos \& Dimitriu, 1999) that is proven by historical accounts (Soloviev et al., 2000) and geoscientific studies (e.g. Scheffers et al., 2008, Vött et al., 2009). Moreover, seasonal changes of the coastline, for example by winter storms, may reach considerable dimensions.

As a result of high-energy impacts, large boulders are dislocated inland from the littoral zone, sometimes forming imbrication trains (e.g. Scheffers et al., 2008). Such displacements have been reported from many other coasts of the world (e.g. Scheffers \& Kelletat, 2003). They are subject to a controversial debate whether their origin is related to tsunami or to storm influence (e.g. Nott, 2003a, Spiske et al., 2008, Goto et al., 2010, Paris et al., 2011).
Several wave transport equations have been developed in order to achieve approximations of wave heights and velocities of extreme events by incorporating boulder values (e.g. Nott, 2003b, Noormets et al., 2004, Benner et al., 2010). Imamura et al. (2008) introduced a modelling approach achieved by experiments in a water channel with cubic and rectangular shaped boulder models. Rolling and saltation were determined as major transport mechanisms. However, the extraction of boulder values often relies on tape-measurements or DGPS point data, but the shape of a boulder is much more complex. Thus, we used terrestrial laser scanning (TLS) to achieve 3Dmodels of dislocated boulders and further parameters of their environment. Furthermore, a monitoring approach is considered to estimate the annual change on selected sites.

Terrestrial laser scanning is an active remote sensing technique, incorporating the method of Light Detection and Ranging (LIDAR). The direct measurement of distances and angles between the sensor and reflecting targets provides highly accurate $3 \mathrm{D}$ point clouds. This method can be applied from the ground surface as TLS. The interpretation of $3 \mathrm{D}$ point clouds is used within the framework of various applications (Vosselmann \& Maas, 2010), for example for 3D-modelling of buildings and

\footnotetext{
* Corresponding author: dirk.hoffmeister@uni-koeln.de
} 
cities, as-built documentation, cultural heritage, forensics, and forest inventories.

\section{In this case, we used TLS}

- in combination with density probes for more reliable and accurate estimations of volume and mass, which are input parameters for wave transport equations.

- for annual comparisons of selected areas to determine movement related to stronger storms during winter time and general gradual changes.

Three selected examples are presented in this contribution.

\section{METHODS}

\subsection{Sites}

TLS field campaigns were carried out every year in late summer from 2008-2011. Selected coastal sites (fig. 1) in western Greece were surveyed within the framework of an interdisciplinary project on palaeo-tsunami impacts along the coasts of the eastern Ionian Sea (Vött et al., 2010). In this paper, we focus on three sites (Fig. 1), which were selected for detailed investigation of dislocated boulders (Gerogombos, Cefalonia Island) and for annual monitoring (Katakolo, Peloponnese Peninsula and Kaminia Beach, Lefkada Island). The study areas were chosen from a set of other sites with regard to essential differences in boulder distribution, coastal configuration, and coast type.

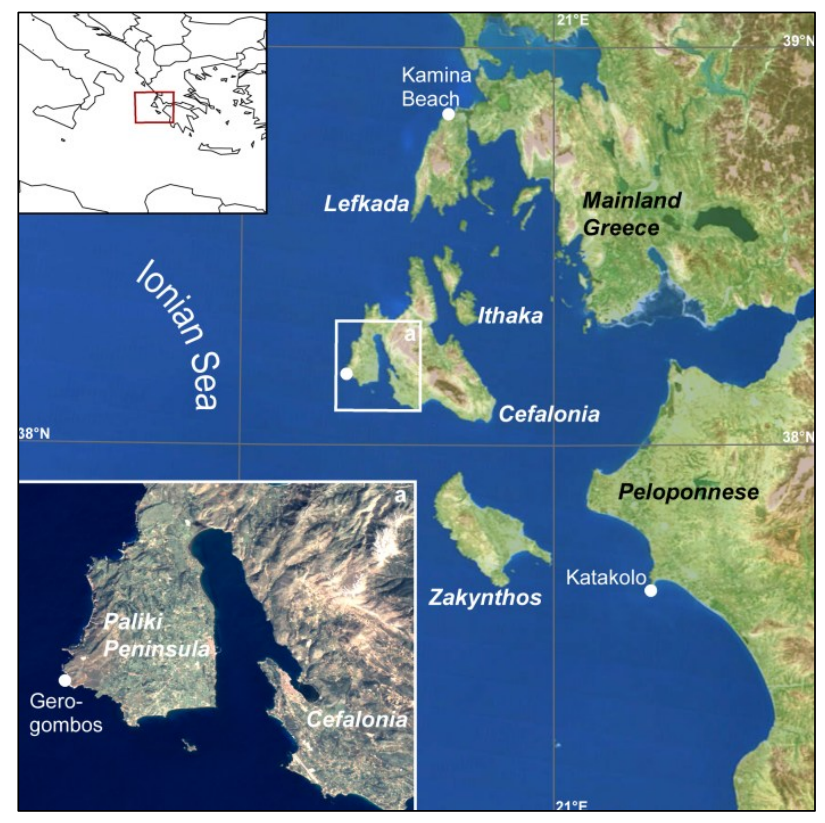

Figure 1. Map of the measurement sites on the Peloponnese Peninsula and the two Ioanian Islands of Cefalonia and Lefkada. Map based on Modis and ASTER GDEM data. Inset map based on Landsat ETM+.

\subsection{Measurements}

In this survey, a Topcon HiPer Pro instrument (TOPCON, 2010), which is a precise differential GPS (DGPS), was used for directly georeferencing (or backsighting) the point clouds. The relative accuracy of the DGPS is about $1 \mathrm{~cm}$, which is essential for the highly accurate transformation of the coordinate system for each scan position. During our survey, positions were recorded in the WGS84 system, UTM Zone $34 \mathrm{~N}$. Apart from each position of the laser scanner, the exact coordinates of one further reference point were measured. With regard to the large survey sites and to avoid an increased number of individual measurements, one large self-made reflector on a ranging pole was used. The inclination of the TLS is recorded by internal sensors.

For the annual measurements, the base point of the local DGPS net was marked by a metal mark and measured 500 times to achieve a mean, enhanced position. All measurements in relation to this base point were situated within the stated accuracy. Additionally, in each year similar scan positions were chosen.

We used a TLS LMS-Z420i Riegl instrument for this survey. The time-of-flight range measurements have an accuracy of $0.6 \mathrm{~cm}$ with a range between $2 \mathrm{~m}$ and $1,000 \mathrm{~m}$ (Kersten et al., 2009). A digital camera, Nikon D200 is mounted on the head of the laser scanner to take RGB-photos, which are usable to colourize the TLS point clouds and to control the results.

In addition to the measurements, density probes of each boulder were taken after completing the scanning process. Density measurements were realized after the Principle of Archimedes in the laboratory, using hand-sized samples (Spiske et al., 2008).

\subsection{Post Processing}

Data from different scan positions were directly georeferenced and merged by the RiSCAN PRO software. We used the iterative closest point (ICP) algorithm, which is implemented in RiSCAN PRO as Multi Station Adjustment (MSA) to enhance this registration (Besl \& McCay, 1992). Furthermore, noise and outliers were removed manually.

Parameters like the mean length of the boulder axes required for the approach were measured manually for each boulder. For the optimal reconstruction and gap-filling of the 3D-model, as well as the accurate determination of the volume of each boulder, the software Geomagic Studio 11 was used. The reconstruction process was visually controlled by the digital photographs. Thus, we created, exported, processed, and finally re-imported a new object for each boulder by manually masking points.

These parameters are incorporated in selected wave transport equations. In this case, equations that rely on the mass of a boulder are chosen. Equations that regard boulder axes are not considered but tested, as well. For all boulders a submerged pretransport scenario is considered (Nott, 2003b). Thus, the mass of a boulder is

$$
m_{b}=V_{b} * \rho_{b}
$$

where

$$
\begin{aligned}
& m_{b}=\text { mass of a boulder } \\
& V_{b}=\text { volume of a boulder } \\
& \rho_{b}=\text { density of the boulder }
\end{aligned}
$$

The minimum velocity, which is needed to move a boulder by sliding, is calculated from the equation of Noormets et al. (2004): 


$$
v_{t}=\sqrt{\frac{2 \mu m_{b} g}{c_{d} a c \rho_{w}}}
$$

where

$$
\begin{aligned}
& \mathrm{v}_{\mathrm{t}}=\text { wave velocity } \\
& \mu=\text { coefficient of friction } \\
& C_{d}=\text { coefficient of drag } \\
& g=\text { gravity } \\
& a, b, c=\text { boulder axes } \\
& \rho_{\mathrm{w}}=\text { density of water }
\end{aligned}
$$

As stated by Imamura et al. (2008) the movement of boulders is better explained by an overturning and saltation movement. For this approach, the equation of Etienne et al. (2011) is regarded, which assumes an overturning:

$$
v_{t}=\sqrt{\frac{0.5 b m_{b} g}{0.5 C_{d} a c^{2} \rho_{w}}}
$$

For these equations, we compared the detailed data from the 3D-reconstruction and the density probes with a mass achieved by multiplying the mean axes of a boulder and estimated densities. For the limestone in the area of Cape Gerogombos a density of $2.3 \mathrm{~g} / \mathrm{cm}^{3}$ is suggested.

Every point cloud of the annual monitoring approach, for both areas, Katakolo and Kaminia Beach were clipped and high resolution digital elevation models (HRDEMs) were established. Afterwards, the surfaces are compared to each other. The results of the comparison were checked visually by the pictures of the mounted camera.

\section{RESULTS}

During the field campaign, TLS and DGPS measurements were carried out. The georeferencing quality was enhanced by the MSA approach in order to achieve an overall standard deviation in the sub-centimeter range. All point clouds were manually filtered and cutted.
For the analysis of the boulders, density samples for every boulder were taken. Gaps in each 3D-model of a boulder were manually filled and the whole model was checked by photos and the original point cloud (fig. 2). The volume of each boulder and the density result in the mass.

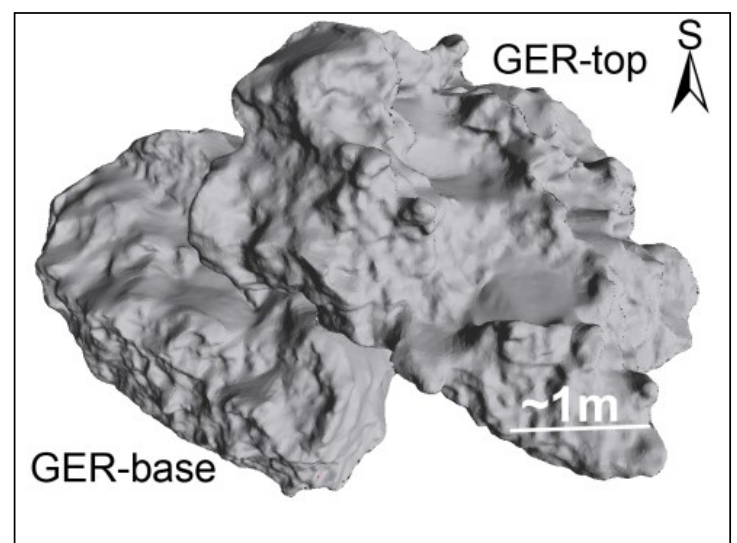

Figure 2. Perspective view of two boulders of Katakolo, lying on top of each other.

The data is used as input parameters for selected wave transport equations. We compared the more accurate input parameters to estimations. Results are shown in Table 3. The comparison of the estimated and reconstructed masses of the boulders already shows considerable differences of about $70 \%$. Thus, the wave velocities in both equations are overestimated, due to the reduced mass. For the case of eq. 2 a mean difference of about $30 \%$ and for eq. 3 of about $80 \%$ is detectable.

The annual monitoring approach was accomplished by

\begin{tabular}{|c|c|c|c|c|c|c|c|c|c|c|c|}
\hline boulder - Id & $\begin{array}{c}\text { calc. } \\
\text { volume } \\
{\left[\mathrm{m}^{3}\right]}\end{array}$ & $\begin{array}{c}\text { est. } \\
\text { density } \\
{\left[\mathrm{g} / \mathrm{cm}^{3}\right]}\end{array}$ & $\begin{array}{c}\text { est. } \\
\text { mass } \\
{[t]}\end{array}$ & $\begin{array}{c}3 \mathrm{D} \\
\text { volume } \\
{\left[\mathrm{m}^{3}\right]}\end{array}$ & $\begin{array}{l}\text { meas. } \\
\text { density } \\
{\left[\mathrm{g} / \mathrm{cm}^{3}\right]}\end{array}$ & $\begin{array}{c}\text { 3D } \\
\text { mass } \\
{[\mathbf{t}]}\end{array}$ & $\begin{array}{c}\text { ratio } \\
\text { est. mass } \\
\text { to } 3 \mathrm{D} \\
\text { mass } \\
{[\%]}\end{array}$ & $\begin{array}{c}\text { wave } \\
\text { velocity } \\
\text { [m/s] } \\
\text { eq. } 2 \text { - } \\
\text { by est. }\end{array}$ & $\begin{array}{c}\text { wave } \\
\text { velocity } \\
\text { [m/s] } \\
\text { eq. } 2 \text { - } \\
\text { by } 3 D \\
\end{array}$ & $\begin{array}{c}\text { wave } \\
\text { velocity } \\
{[\mathrm{m} / \mathrm{s}]} \\
\text { eq. } 3 \text { - } \\
\text { by est. }\end{array}$ & $\begin{array}{c}\text { wave } \\
\text { velocity } \\
{[\mathrm{m} / \mathrm{s}]} \\
\text { eq. } 3 \text { - } \\
\text { by } 3 \mathrm{D}\end{array}$ \\
\hline GER-ST5 & 9.79 & 2.3 & 22.52 & 4.50 & 2.52 & 11.37 & 198 & 6.68 & 4.91 & 13.67 & 7.09 \\
\hline GER-top & 8.82 & 2.3 & 20.29 & 4.95 & 2.52 & 12.50 & 162 & 6.25 & 5.07 & 11.96 & 6.86 \\
\hline GER-base & 7.20 & 2.3 & 16.56 & 3.77 & 2.52 & 9.50 & 174 & 5.79 & 4.53 & 9.72 & 5.38 \\
\hline$\varnothing$ & 8.60 & 2.3 & 19.79 & 4.41 & 2.52 & 11.12 & 178 & 6.68 & 4.91 & 13.67 & 7.09 \\
\hline
\end{tabular}
establishing a local DGPS-network with the same base point for every year. All point clouds of every year fit together. However, the registration of every point cloud from a certain site is enhanced by the MSA. HRDEMs are established afterwards, and compared to each other. Figure 4 shows the results for the area of Katakolo with according pictures of one selected area and Figure 5 shows the area of Kaminia Beach.

Table 3: Results of the different estimations (est.) and calculations by 3D-reconstruction (3D) of the dislocated boulders. 


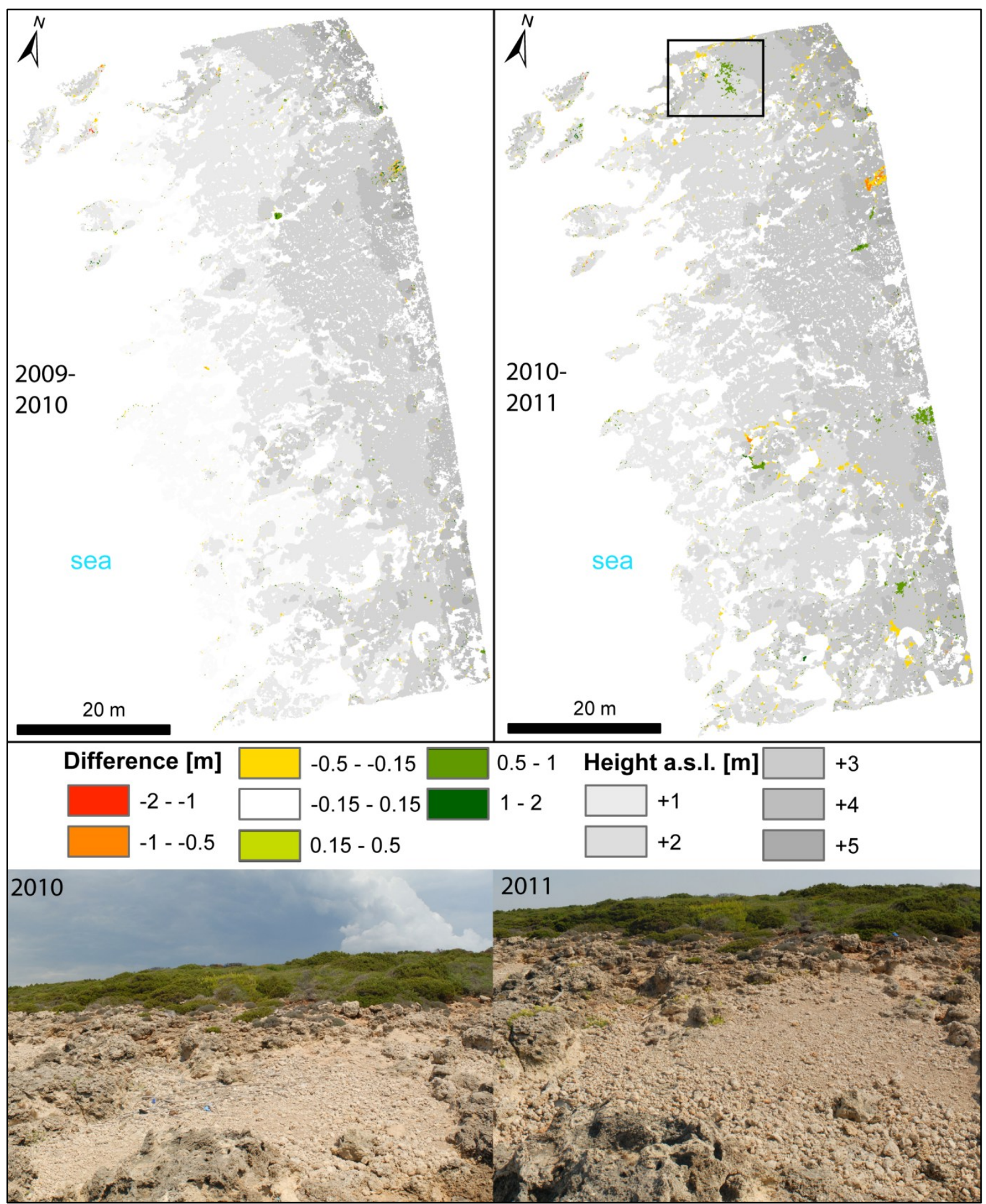

Figure 4. Two annual comparisons of the area of Katakolo, Peleponnes Peninsula. According pictures of a selected area (white box) are shown below. Gravel was reordered in this time span.

At Katakolo, only slightly changes are visible for the comparison of 2009 to 2010. Major changes occur, due to a rusty barrel moved into the area. Bigger changes can be detected for the comparison between 2010 and 2011. Gravel is dislocated at several areas, as well as bigger stems. In Figure 4 exemplary pictures from nearly the same scan position are shown. However, due to slightly changes of these scan positions different areas are measured and affect the triangulation process and thus the results. Small areas with slightly changes, in particular at the sea side are concerned as not changing areas.
In opposite to the punctual changes at Katakolo, the area of Kaminia Beach, which consists of gravel and sand, shows considerable changes in most parts of the littoral zone, as presented in Figure 5. The sea weed, which covered a large part of the beach in 2009 has mostly disappeared in 2010. At the same time, a deposit of sandy sediments was considerably reduced up to $1 \mathrm{~m}$ in size. Another sand cover close to a wall was replaced by coarse-grained material in 2010 and gravel was accumulated. Some pieces of gravel with $30-50 \mathrm{~cm}$ diameter have also been displaced. The comparison of 2010 and 2011 
shows minor changes. Again, larger gravel is moved at the western part of the area, whereas sand is reordered at the eastern part of the area. We assume that the observed changes mainly arise, due to winter storm events.

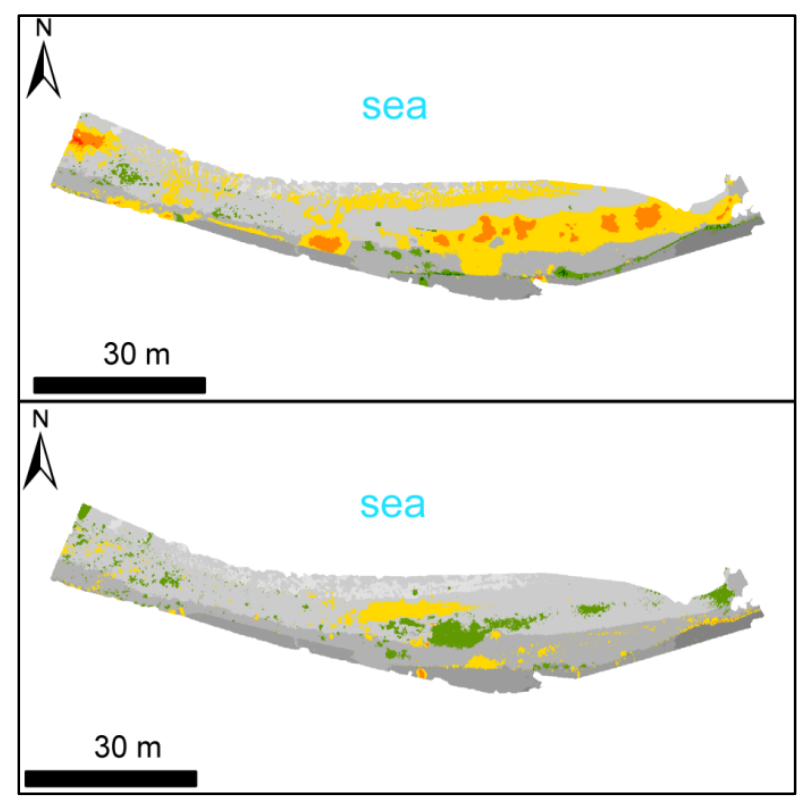

Figure 5: Annual changes of Kaminia Beach; top: 2009-2010 and bottom: 2010-2011 (legend see fig. 4).

\section{DISCUSSION}

For the measurement of geomorphological features, such as high-energy wave displaced boulders, terrestrial laser scanning (TLS) is an appropriate and reliable tool to achieve parameters and topographic maps. The method is additionally usable for annual coastal monitoring, as already shown in literature (e.g. Rosser et al., 2005). Georeferencing and registration of point clouds by direct measurements of the scan position by DGPS, as well as using a further reflector pole turned out to be a practicable method for this kind of geomorphologic field surveys. In addition, the registration and merging for annual data, connected by the marked base point worked well and is precise.

The 3D-reconstruction of dislocated boulders at Gerogombos is an enhancement in accuracy for mass determination. However, the bottom side or other areas, which are not reachable by the scanning device, are estimated areas. The established 3Dmodels are still more accurate than cubic assumptions by multiplying mean axes. As shown in Figure 2, the boulders are very much rounded, which is mainly the reason for the big differences in volume and mass estimation presented in Table 3. The accurate determination of density has a minor impact on the results. For enhanced wave transport equations or modelling approaches, the TLS method is additionally capable for the extraction of further parameters, e.g. distance to sea, height above current sea level or a roughness coefficient (Pignatelli et al., 2010). The results fit to other investigations on dislocated boulder in the Mediterranean (e.g. Scicchitano et al., 2007).

TLS is additionally capable for monitoring approaches at coastal areas (Rosser et al., 2005, Lindenbergh et al., 2011). We showed that annual changes occur at both sites, Katakolo and Kaminia Beach. The area of Katakolo shows minor changes, but consists of several mid-size boulders at the edge of the area, which showed no movement for the past years. Thus, it is highly likely that a bigger event has moved these boulders. Overall, the post- processing of point clouds at beaches and flat, very rough coastal areas turned out to be problematic because of noise effects by water and shadowing effects. The pictures of the mounted camera were very helpful to control and determine areas of actual change. However, our studies show that monitoring of gradual coastal changes is possible.

\section{CONCLUSION}

Our studies show that TLS is capable to accurately estimate volumes and masses of boulders. The mass of boulders calculated by means of 3D-reconstruction of volume and density data turned out to be smaller (up to $50 \%$ ) than was previously estimated on the base of tape-measurements and raw approximations. Incorporating these accurate mass data into wave transport equations leads to modelled wave heights and velocities, which are considerably smaller, due to less mass of the boulders.

Furthermore, monitoring of several locations using a multitemporal approach is a helpful tool to document annual coastal changes. Net elevation changes were detected by comparing HRDEMs from different years. Our studies show that the application of TLS in different littoral settings is an appropriate tool for monitoring, with slightly limitations at rough areas.

\section{ACKNOWLEDGEMENTS}

We gratefully acknowledge financial support of the project "Quaternary tsunami events in the eastern Ionian Sea reconstructing and modelling extreme events based on interdisciplinary geo-scientific investigations" (VO 938/3-1) by the German Research Foundation (DFG). We additionally thank RIEGL Laser Measurement GmbH (Austria) and Topcon $\mathrm{GmbH}$ (Germany) for continuous support.

\section{REFERENCES}

Benner, R., Browne, T., Bruckner, H., Kelletat, D. \& Scheffers, A., 2010. Boulder Transport by Waves: Progress in Physical Modelling. Zeitschrift Fur Geomorphologie, 54, 127-146. doi: 10.1127/0372-8854/2010/0054s3-0022.

Besl, P.J. \& McKay, N.D., 1992. A method for registration of 3D shapes. Ieee Transactions on Pattern Analysis and Machine Intelligence, 14, 239-256.

Etienne, S., Buckley, M., Paris, R., Nandasena, A.K., Clark, K., Strotz, L., Chagué-Goff, C., Goff, J. \& Richmond, B., 2011. The use of boulders for characterising past tsunamis: Lessons from the 2004 Indian Ocean and 2009 South Pacific tsunamis. Earth-Science Reviews, 107, pp. 76-90. doi: 10.1016/j.earscirev.2010.12.006.

Goto, K., Miyagi, K., Kawamata, H. \& Imamura, F., 2010. Discrimination of boulders deposited by tsunamis and storm waves at Ishigaki Island, Japan. Marine Geology, 269, pp. 3445. doi: 10.1016/j.margeo.2009.12.004.

Imamura, F., Goto, K. \& Ohkubo, S., 2008. A numerical model for the transport of a boulder by tsunami. Journal of Geophysical Research-Oceans, $113 . \quad$ doi: 10.1029/2007jc004170. 
Kersten, T.P., Mechelke, K., Lindstaedt, M. \& Sternberg, H., 2009. Methods for Geometric Accuracy Investigations of Terrestrial Laser Scanning Systems Photogrammetrie Fernerkundung - Geoinformation, pp. 301-315.

Lindenbergh, R.C., Soudarissanane, S.S., De Vries, S., Gorte, B.G.H. \& De Schipper, M.A., 2011. Aeolian Beach Sand Transport Monitored by Terrestrial Laser Scanning. Photogrammetric Record, 26, pp. 384-399. doi: 10.1111/j.14779730.2011.00659.x.

Noormets, R., Crook, K.A.W. \& Felton, E.A., 2004. Sedimentology of rocky shorelines: 3. Hydrodynamics of megaclast emplacement and transport on a shore platform, Oahu, Hawaii. Sedimentary Geology, 172, pp. 41-65. doi: 10.1016/j.sedgeo.2004.07.006.

Nott, J., 2003a. Tsunami or Storm Waves? - Determining the Origin of a Spectacular Field of Wave Emplaced Boulders Using Numerical Storm Surge and Wave Models and Hydrodynamic Transport Equations. - Journal of Coastal Research, 19 (2), pp. 348-356.

Nott, J., 2003b. Waves, coastal boulder deposits and the importance of the pre-transport setting. - Earth and Planetary Science Letters, 210 (1-2), pp. 269-276.

Papazachos, B. C., \& P. P. Dimitriu, 1991. Tsunamis in and near Greece and their relation to the earthquake focal mechanisms, Natural Hazards, 4(2), pp. 161-170.

Paris, R., Naylor, L.A. \& Stephenson, W.J., 2011. Boulders as a signature of storms on rock coasts. Marine Geology, 283, pp. 111. doi: 10.1016/j.margeo.2011.03.016.

Pignatelli, C., Piscitelli, A., Damato, B. \& Mastronuzzi, G., 2010. Estimation of the value of Manning's coefficient using Terrestrial Laser Scanner techniques for the assessment of flooding by extreme waves. Zeitschrift für Geomorphologie, Supplementary Issues, 54, pp. 317-336. doi: 10.1127/03728854/2010/0054S3-0030.

Riegl, 2010. LMS Z420i.

http://riegl.com/uploads/tx_pxpriegldownloads/10_DataSheet_Z 420i_03-05-2010.pdf (12 Nov. 2011).

Rosser, N.J., Petley, D.N., Lim, M., Dunning, S.A. \& Allison, R.J., 2005. Terrestrial laser scanning for monitoring the process of hard rock coastal cliff erosion. Quarterly Journal of Engineering Geology and Hydrogeology, 38, pp. 363-375. doi: 10.1144/1470-9236/05-008.

Scheffers, A. \& Kelletat, D. 2003. Sedimentologic and geomorphologic tsunami imprints worldwide - a review. EarthScience Reviews, 63, pp. 83-92. doi: 10.1016/s00128252(03)00018-7.

Scheffers, A., Kelletat, D., Vött, A., May, S.M. \& Scheffers, S., 2008. Late Holocene tsunami traces on the western and southern coastlines of the Peloponnesus (Greece). Earth and Planetary Science Letters, 269, pp. 271-279. doi: 10.1016/j.epsl.2008.02.021.

Scicchitano, G., Monaco, C. \& Tortorici, L., 2007. Large boulder deposits by tsunami waves along the Ionian coast of south-eastern Sicily (Italy). Marine Geology, 238, pp. 75-91. doi: 10.1016/j.margeo.2006.12.005.
Soloviev, S.L., Solovieva, O.N., Go, C.N., Kim, K.S. \& Shchetnikov, N.A., 2000. Tsunamis in the Mediterranean Sea 2000 B.C. - 2000 A.D. - 1. ed., Kluwer, Dordrecht, the Netherlands, 237 pp.

Spiske, M., Borocz, Z. \& Bahlburg, H., 2008. The role of porosity in discriminating between tsunami and hurricane emplacement of boulders - A case study from the Lesser Antilles, southern Caribbean. Earth and Planetary Science Letters, 268, pp. 384-396. doi: 10.1016/j.epsl.2008.01.030.

TOPCON, 2010. HiPer Pro.

http://www.topconpositioning.com/products/gps/receivers/hiper -pro. (12 Nov. 2011).

Vött, A., Brückner, H., Brockmüller, S., Handl, M., May, S.M., Gaki-Papanastassiou, K., Herd, R., Lang, F., Maroukian, H., Nelle, O. \& Papanastassiou, D., 2009. Traces of Holocene tsunamis across the Sound of Lefkada, NW Greece. Global and Planetary Change, 66, pp. 112-128. doi: 10.1016/j.gloplacha.2008.03.015.

Vött, A., Bareth, G., Brückner, H., Curdt, C., Fountoulis, I., Grapmayer, R., Hadler, H., Hoffmeister, D., Klasen, N., Lang, F., Masberg, P., May, S.M., Ntageretzis, K., Sakellariou, D. \& Willershäuser, T., 2010. Beachrock-type calcarenitic tsunamites along the shores of the eastern Ionian Sea (western Greece) case studies from Akarnania the Ionian Islands and the western Peloponnese. Zeitschrift für Geomorphologie N.F., 54, pp. 1-50. doi: 10.1127/0372-8854/2010/0054S3-0018.

Vosselmann, G. \& Maas, H.-G., 2010. Airborne and terrestrial laser scanning. - 1. ed., Whittles Publishing, Dunbeath, UK, $318 \mathrm{pp}$. 